\title{
The Politics of Public Health: A Rapid Review of the Impact of Public Health Reform on Population Health Outcomes
}

\author{
Charlotte Riordon ${ }^{1}$, Sionnach Hendra ${ }^{1}$ \& Christine Johnson ${ }^{2}$ \\ ${ }^{1}$ Rankin School of Nursing, St. Francis Xavier University, Antigonish, Nova Scotia, Canada \\ ${ }^{2}$ Department of Human Nutrition, St. Francis Xavier University, Antigonish, Nova Scotia, Canada \\ Cite as: Riordon, C., Hendra, S. \& Johnson, C. (2021). The Politics of Public Health: A Rapid Review of \\ the Impact of Public Health Reform on Population Health Outcomes. Witness: The Canadian Journal of \\ Critical Nursing Discourse, Vol 3(1), pp 98-115. https//doi.org/10.25071/2291-5796.66
}

\begin{abstract}
Canada's public health (PH) systems are vulnerable to constant system and structural changes, influenced by political and economic factors. This rapid review examines how $\mathrm{PH}$ system restructuring impacts population health outcomes, with special consideration of health equity. Due to a lack of Canadian evidence, international research was examined to produce recommendations for Canadian nurses, researchers, and decision-makers. Evidence indicates that $\mathrm{PH}$ spending and $\mathrm{PH}$ system organization have important impacts on population health outcomes and suggests $\mathrm{PH}$ reform has a negative impact on health equity. Opportunities for advocacy, activism, lobbying, and capacity building to achieve health equity are discussed. Nurses, in a unique position between public policy and the lives of those they care for, are presented with the opportunity to effect social change through political action and to work across disciplines to address inequities. We encourage researchers and decision-makers to prioritize looking more deeply at the impact of PH reform.
\end{abstract}

Keywords: health equity; population health outcomes; public health reform; public health nursing

\section{Introduction}

Improved population health and reduced health inequities are the ultimate goals of the public health system in Canada (Pinto et al., 2012). Public health systems are complex adaptive networks involving federal, provincial, territorial, and municipal governments. These systems include numerous departments, agencies, and organizations working together through a public health approach to deliver programs and public health services to
Canadians (Canadian Public Health Agency [CPHA], 2019). The public health approach places health promotion, health protection, population health surveillance, and the prevention of death, disease, injury, and disability as the central tenets of all related initiatives (CPHA, 2017). Public health's role in promoting population health and reducing population health inequities and the tools to achieve these goals have been clearly outlined (National Collaborating Centre for Determinants of Health [NCCDH], 2013). However, public 
health systems across Canada have been undergoing significant reform resulting in numerous challenges and unclear impacts on population health.

\section{Public Health Reform}

In this paper, we use the term, public health reform, to describe the restructuring of public health systems in any way, including financial, organizational, or structural changes. Although some public health system changes can lead to improvements, many are likely to have an adverse impact on health equity when the primary focus is on efficiency through integration and consolidation (NCCDH, 2018b). From budget cuts to centralization, changes to public health are being noticed in Canada; however, to date there is little Canadian evidence to inform the impact of these changes. With continued shifting in public health systems across the country, this research is timely for public health professionals, researchers, and policy/decision-makers (Guyon et al., 2017; Fafard, 2018; CPHA, 2019).

Public health system funding historically occupies only a small percentage of healthcare spending in Canada. Centralization and other structural and organizational changes, along with challenges to the roles and responsibilities of Canada's Chief Medical Officers of Health (Fafard, 2018), have led researchers and public health professionals to declare that Canada's public health system is in crisis or, more specifically, "under attack" (Guyon \& Perreault, 2016), "under siege" (Potvin, 2014) and weakened (Fiset-Laniel et al., 2020; Guyon et al., 2017). Public health experts continue to call for action to address the fact that current public health systems in Canada underperform in working to create healthier populations. Despite the urge for action after SARS (Naylor et al., 2003), the issues raised at that time persist (Guyon et al., 2017). One major factor contributing to the weakening of public health systems is the reform of organizational structures, such as centralization in Alberta in 2008 and in Nova Scotia in 2015. These system reforms lead to an erosion of public health resources, inconsistent public health leadership, and a lack of supportive structures, which can ultimately impact public health teams' progress in addressing complex health issues like health equity (NCCDH, 2018a).

Researchers have made significant contributions to the literature on public health performance, but overall, the impact of public health system restructuring on health outcomes, especially related to health equity, is still not well understood (Mays et al., 2009; Scutchfield \& Ingram, 2013). Using a rapid review methodology and concepts from public health systems and services research, this paper seeks to answer the following question: How does the restructuring of public health systems impact population health outcomes?

\section{Public Health Systems and Services Research}

Public health systems and services research (PHSSR) is a field of study which examines the organization, financing, and delivery of public health services (Mays et al., 2003). The goals of PHSSR, like those of the public health system, include improving population health and reducing health inequities (Strosher et al., 2012).

Improvement in the public health system is hampered by a lack of evidence informing the effectiveness of public health practice, organization, and financing (Mays et al., 2003). By studying the impact of public health system reform on population health, we can develop an evidence base to support public health professionals, including nurses, in advocacy efforts for appropriate public health system organization and spending (Strosher et al., 2012). Further, PHSSR can contribute to the development of evidence-based accountability structures which will allow decision-makers to make informed decisions when restructuring.

\section{Methods}

A rapid review of the literature was conducted. Rapid reviews have been used for more than a 
decade in the field of public health, as this method allows researchers to produce timely knowledge translation for practitioners and policymakers (Schick-Makaroff et al., 2016). The aim of this rapid review was to answer the question: How does the restructuring of public health systems impact population health outcomes? Special attention was given to the role of health equity in each of the included articles, as health equity is a crucial component of public health and should be considered alongside population health outcomes when discussing public health reform.

\section{Search Terms and Inclusion/Exclusion Criteria}

An iterative search process was used during this rapid review. The following search terms were used: "public health system" OR "public health renewal" OR "public health reform" OR "public health structure" OR "public health infrastructure" OR "public health administration" OR "public health workforce" OR "health equity" AND "population health outcomes." In the first phase of the review, these search terms were used with AND "canad*" to capture Canadian literature. In the second phase, the first search was repeated with AND "health outcomes" instead of "population health outcomes" to capture any relevant literature which may have inadvertently used the terms interchangeably. Finally, as the first and second searches yielded only one relevant article, a third phase search was completed without "canad*" to examine international research.

The searches were limited to English, full-text, peer-reviewed articles published between January 2010 and May 2018. Due to the limited timeframe in which this review was completed, this date range was chosen after preliminary searches for articles published from 2013 to 2018 produced limited results. The searches were conducted from 19 May 2018 to 20 June 2018 and included the Cumulative Index to Nursing and Allied Health Literature (CINAHL), Web of Science, PubMed/Medline,
Canadian Business in Current Affairs, and Google Scholar.

After duplicates (139) were removed, 234 articles underwent initial screening via title and abstract. Articles were excluded if they were interventions-focused and/or not empirical. Articles were included if they examined public health system reform and population health outcomes. These inclusion/exclusion criteria were set to ensure relevance to the research question and to achieve a manageable scope. Twelve relevant articles were identified for fulltext review yielding three (Bambra et al., 2014; Guyon \& Perreault, 2016; Thomson et al., 2017) articles selected for inclusion. The remaining nine articles were excluded for not addressing the research question (2), not being relevant (1), being an editorial (1), not being outcomesfocused (3), or for not addressing the research question empirically (1). The reference lists of included articles were hand-searched, yielding an additional four included texts (Erwin et al., 2011; Erwin et al., 2012; Mays \& Smith, 2011; Singh, 2014) for a total of seven articles.

\section{Critical Appraisal}

This rapid review yielded two systematic reviews, one scoping review, one case control study, and three cohort studies. Each article was independently, critically appraised by two reviewers using appropriate tools. The Health Evidence, Quality Assessment Tool (Health Evidence, 2016) was used for systematic reviews, the Joanna Briggs Institute (JBI) tool for text and opinion papers (JBI, 2017) was used for the scoping review, and Critical Appraisal Skills Programme (CASP) tools (CASP, 2018a; CASP, 2018b) were used for the case control and cohort studies. Of the seven articles, four were appraised as strong (Bambra et al., 2014; Erwin et al., 2011; Erwin et al., 2012; Mays \& Smith, 2011); two, as moderate (Singh, 2014; Thomson et al., 2017; and one, as fair (Guyon \& Perreault, 2016). See Table 1 for an overview of the search process. 


\section{Analysis and Synthesis}

Tables were developed to organize the contents of each included article. The following details were extracted from each article: data source(s), analytic method, independent variable(s), dependent/outcome variable(s), and key findings (See Tables 2 and 3). The guiding question for data synthesis was: What are the overall conclusions from all the included research (Dobbins, 2017)? Key findings from each article were grouped into two themes: public health spending and public health system organization. Finally, a table was developed to organize the data surrounding the role of health equity in each of the included articles (See Table 4). For clarity, primary articles within the included review articles were accessed to provide context to our results.

\section{Results}

\section{How Does the Restructuring of Public Health Systems Impact Population Health Outcomes?}

This review yielded only one relevant Canadian article (Guyon \& Perreault, 2016) addressing our research question. However, Guyon and Perreault (2016) highlighted primarily international data, indicating that Canadian research on this topic is significantly lacking. The findings of Guyon and Perreault (2016) were synthesized along with the available international research and grouped into two themes: public health spending and public health system organization. Special attention was then given to how health equity was incorporated in each article.

\section{Public Health Spending}

When considering public health system reform, spending is a common concept which is relatable and understandable by all Canadians. Our research showed that increases in public health spending contribute to improvement in some population health outcomes. For example, in the United States (U.S.), increases in state-level aggregate local health department (LHD) expenditures per capita were associated with decreased rates of infectious disease morbidity (Erwin et al., 2011; Erwin et al., 2012; Singh, 2014) and preventable death (Erwin et al., 2012). Erwin and colleagues (2012) found that a 7.4\% decline in infectious disease mortality resulted from each $\$ 10$ increase in expenditures, with the same spending associated with a $1.5 \%$ drop in years of potential life lost. Increased funding for LHDs is related to decreased rates of infant death and deaths due to heart disease, diabetes, and cancer (Mays \& Smith, 2011), as well as decreases in cardiovascular deaths (Erwin et al., 2012; Singh, 2014). Of note, these studies do not explore health inequities in these population health outcomes; therefore, there is no way to determine if the benefit of increased spending in public health systems benefits the population as a whole or if it is concentrated in particular groups.

The systematic review by Singh (2014), though only moderate in quality, is congruent with the findings of the current rapid review. Singh (2014) identified 10 studies examining the relationship between population health outcomes and public health spending published between 1985 and 2012. Specifically, included studies in Singh's (2014) review used measures of public health spending such as total LHD funding per capita, total real maternal and child expenditures per capita, and percent share of public revenue allocated to LHDs, among others. Positive associations were found between LHD expenditures and reduced rates of infant mortality and deaths due to preventable illnesses such as cardiovascular disease, cancer, and diabetes (Grembowski et al., 2010; Mays \& Smith, 2011). As another example, when federal and state immunization financing was aligned with local needs across different U.S. states, childhood immunization coverage rates were improved (Ransom et al., 2012).

Due to the complexity of public health systems, Singh (2014) reports that the mechanisms by which public health spending positively impacts these population health outcomes is unclear, 
indicating that future research in this area is necessary. Singh (2014) notes that the improved efficiency that results from increased public health spending may be a key factor in explaining the relationship between spending and population health outcomes.

Financial resources are an important component of the organizational capacity of public health systems and may contribute to improved population health outcomes through access to greater resources including recommended practices and procedures (Singh, 2014). Focusing public health resources on subpopulations with the greatest needs may also contribute to overall improvements in population health outcomes.

\section{Public Health System Organization}

Improvements in public health system organization (e.g., increased staffing, improved infrastructure) lead to better population health outcomes. Erwin and colleagues (2011) found that mean full-time equivalents (FTEs) at the state level fell between 1997 and 2005 in the U.S. After examining numerous public health outcomes including smoking prevalence, cancer deaths, and years of potential life lost, Erwin and colleagues (2011) noted a statistically significant negative association between increasing FTEs per capita and decreased deaths due to cardiovascular disease, indicating that higher staffing levels are associated with fewer cardiovascular deaths (Erwin et al., 2011). Further, higher staffing per population served ratios result in more effective delivery of public health services (Hyde \& Shortell, 2012), likely contributing to improved population health. Organizational factors such as having a population size between 50,000 and 500,000 are a strong predictor of public health system performance (Hyde \& Shortell, 2012), and specific administrative features such as workforce development and inter-organizational relationships and partnerships are all related to increased productivity in public health systems (Brownson et al., 2012). Productivity, which may be considered a neoliberal term, is used here to describe the relationship between public health system structures (such as policy, legislation, and administrative infrastructure) and processes (such as advocacy, health promotion and protection, and direct services) (Guyon \& Perreault, 2016). However, due to the lack of primary studies in Canada, it is difficult to assess how public health system organization impacts population health outcomes in this country.

While all other included articles in this review were either observational or review papers, Thomson and colleagues (2017) used a casecontrol study design to examine the impacts of public health system reform on population health outcomes. The Rwandan Ministry of Health $(\mathrm{RMOH})$ Partners in Health (PIH) intervention was examined in Kirehe/S. Kayonza, a rural area with some of the least favourable health outcomes in Rwanda. The RMOH-PIH intervention involved compensating community health workers and improving staffing and infrastructure. Population health outcome indicators included neonatal, infant, and underfive mortality, diarrhea or fever in children less than five years old, stunting and wasting in children under five, etc. (Thomson et al., 2017). Kirehe/S. Kayonza was compared to other rural areas in Rwanda where the RMOH-PIH intervention was not implemented. Overall, improvements in health system outputs and outcomes improved in both groups, but the intervention group exhibited greater improvements in population health outcomes such as decreased rates of diarrhea, acute respiratory infection, and fever (Thomson et al., 2017). Although the context of this research and the population health outcomes under study are quite different from the Canadian public health system, Thomson and colleagues (2017) provide an important look at public health systems and population health which is useful for this research. Specifically, they highlight evidence of the benefits of strong public health systems, particularly in rural areas experiencing poverty (Thomson et al., 2017), a context frequently observed in Canada's northern and rural communities. 


\section{The Canadian Journal of Critical Nursing Discourse}

See it. Speak it. Write it. Change it.

\section{Where is Health Equity?}

The findings of this review indicate that there is limited good quality Canadian research available examining the impacts of public health reform on health equity. Only one of the included articles used health equity as an outcome variable. This international umbrella review of systematic reviews suggests inconclusive or negative impacts due to health care system reforms (Bambra et al., 2014). Health care systems that increased private insurance usage had greater inequalities in access to health care, and increased out-of-pocket payments were associated with greater impoverishment (Gelormino et al., 2011). Conversely, free or publicly funded managed care contributed to reduced socioeconomic inequalities in health (Gepkens \& Gunning-Schepers, 1996). Privatization is seen to negatively impact health equity (Bambra et al., 2014). Specifically, privatization in the U.S. through for-profit health care providers resulted in reduced access to health care for vulnerable populations (Braithwaite et al., 2011). Bambra and colleagues (2014) found that marketization has negative and inconclusive impacts on health equity. Marketization in Sweden resulted in greater inequalities in utilization of and access to health care (Hanratty et al., 2007), while inconclusive findings were noted by Fotaki and colleagues (2008). The integration of health and social services has inconclusive impacts on health equity (Bambra et al., 2014). For example, a school partnership intervention for deprived areas in the U.S. had no impact on health, while community partnership programs in the Netherlands had positive effects on health behaviours (Hayes et al., 2012). Although Bambra and colleagues (2014) primarily examined health care systems rather than specifically public health systems, their findings are relevant for informing this review as public health makes up an important part of many health care system organizations.

While Bambra and colleagues (2014) found health care reform had negative and/or inconclusive impacts on health equity, there is some evidence suggesting that increases in public health spending can meaningfully reduce racial disparities (Singh, 2014). Specifically, public health spending in the form of LHD expenditures is related to decreased mortality rates for black populations in the U.S. (Grembowski et al., 2010).

Although Thomson and colleagues (2017) did not identify health equity as an outcome variable, they found that the RMOH-PIH intervention produced the highest rates of improvements in health outcomes, including rates of diarrhea, acute respiratory infection, and fever, in people with lower incomes. From this, it can be inferred that improvements in the public health system organization during the RMOH-PIH had a positive impact on health equity.

Guyon and Perreault (2016) identified equity as a component of public health performance but recognized its absence in PHSSR. Specifically, PHSSR often focuses on the productivity of public health performance rather than equity (Guyon \& Perreault, 2016). The remaining articles included in this review (Erwin et al., 2011; Erwin et al., 2012; Mays and Smith, 2011) did not identify health equity as a component of population health outcomes. Considering the importance of health equity in the fields of public and population health, its absence in research is striking.

\section{Discussion}

In this paper, we explore how public health reform impacts population health outcomes in Canada. However, due to a lack of Canadian primary research articles on this topic, we also included related international research. The data from one Canadian article and six international articles were critically appraised, analyzed, and synthesized, highlighting important connections between public health reform and population health outcomes. Factors such as public health spending and public health system organization, including staffing, infrastructure, and population 
size, all impact population health outcomes. Importantly, it is unclear if these structural changes are positively impacting health equity. These findings are useful for contributing to future research priorities and social policy, as well as providing a foundation for advocacy by public health professionals.

\section{Implications}

\section{Research}

Research (and funding for that research) is needed to explore how Canada's changing public health systems have impacted and continue to impact population health outcomes. To support applied public health research, an indepth understanding of the research-practicepolicy interface is needed (McLaren et al., 2019). Further, researchers need to be supported through time and resources to develop collaborative partnerships with public health practitioners, health care systems, governments, universities, and communities. With adequate time, resources, and partnerships, researchers can develop autonomy and intersectoral research capacity (McLaren et al., 2019). Researchers must work closely with public health leaders, specifically, by engaging them in the research process and working together to implement research recommendations. Public health stakeholders such as managers, directors, and decision-makers can advocate for the prioritization of high quality evidence in the field of PHSSR. Specifically, we should aim to develop evidence-informed accountability structures and organizational frameworks for public health reform.

The role of nurses in this area of research is also crucial for understanding the impacts of public health reform. The connection between public health reform, public health nurses, and population health outcomes is not well understood and requires further exploration through research (Kirk, 2020). However, we do know that historic underfunding of public health units impacts public health nurses when providing adequate and appropriate care for their communities (Beaudet et al., 2011; Falk-Rafael \& Betker, 2012; Schofield et al., 2010). With public health system funding being one aspect of public health reform, this knowledge provides an important starting point for continued research.

We encourage researchers to prioritize looking more deeply at the impact of public health reform on population health outcomes and health equity and to explore ways in which the public health system can be safeguarded from neoliberal influences, political changes, and restructuring. In the future, PHSSR can explore the intersection of changes to structure and spending in other sectors/systems which impact health outcomes.

\section{Public Health Professionals}

Practitioners at all levels can share the findings of this rapid review and highlight the lack of Canadian evidence about the impact public health reform has on population health outcomes and health equity. Public health associations are safe spaces offered to public health professionals for advocacy based on a credible, inherently evidence-informed, platform (CNPHA, 2019), and are one way for public health professionals to engage with this work. Public health professionals can support the CPHA and their provincial/territorial public health associations through membership and contributing to position statements when there is a call for feedback. The 2019 CPHA position statement on public health system reform highlights recommendations for research and development, government organizations and health authorities, as well as public health professionals, such as focusing on assessing return on investment of interventions or incorporating a health-in-all-policies approach (CPHA, 2019). Similarly, the Community Health Nurses of Canada (CHNC) is another organization that is a source of support specifically for community health nurses. Through the CHNC, nurses can have a voice in identifying and responding to issues, such as public health reform, that impact their community. 
Public health professionals require support in advocacy, activism, and lobbying efforts through training, access to politicians, and financing to build capacity (Demaio \& Marshall, 2018). Social lobbyists must be able to understand and "navigate the legislative process, communicate across the social-political divide, and influence policy makers" (Demaio \& Marshall, 2018, p. 1559). Nurses, who are in a unique position between public policy and the lives of those they care for, are presented with the opportunity to effect social change through political action. This opportunity has been considered a "moral obligation" (McGibbon \& Lukeman, 2019). However, neoliberal dynamics dominate the healthcare and education systems, inhibiting nurses' ability to be activists (Buck-McFadyen \& MacDonnell, 2017).

\section{Health Equity}

As advocates, public health professionals aim to promote health equity; one way to do this is through effective data sharing of population demographics, such as age, gender, race, income, and self-reported physical and mental health (Andruszkiewicz et al., 2019). Utilizing awareness, communication, and collaboration, public health professionals can engage with community partners and organizations to transfer research knowledge and to enact social change (Andruszkiewicz et al., 2019). Further, it is important for public health organizations to build capacity for public health practitioners in advocating for appropriately resourced social services to achieve health equity. It is likely that those who are most marginalized will see the largest health gains from increases in social spending (Dutton et al., 2018).

Public health professionals cannot act alone in the pursuit of health equity. The reduction of health inequity in Canada will be possible when public policy emphasizes the social determinants of health with an understanding of the impact of money, power, and resources (Raphael, 2017). Healthcare reform in Canada has been guided by neoliberal principles such as efficiency, privatization, and corporatization (McGibbon \&
Lukeman, 2019). Government agendas can impact the work of public health by emphasizing results-oriented ideologies and prioritizing shortterm measurable outcomes to the exclusion of health equity and social justice (Kirk et al., 2014). Public health professionals, leaders, and government officials must work together to recognize the roles of government operations and the economic system in shifting how health equity is understood at the policy and public levels (Raphael, 2015).

Commitment to health equity and social justice are important values in public health (PHAC, 2008). However, policy-makers and public health practitioners may have difficulty addressing the deeper questions related to social justice, preferring instead to focus on issues of health equity which are perceived as proximal, neutral, and objective, such as access to public health resources (Smith et al., 2018). When we fail to ask why health inequities exist, we fail "to confront uncomfortable structural injustices," thus risking the perpetuation of such inequities (Smith et al., 2018, p. 640). Moving forward, we must be reminded of our commitment to both health equity and social justice.

\section{Social Policy}

Ultimately, changes in social policy will be required to improve population health outcomes, and a health-in-all policies approach has been suggested as a means to this end (Baum et al., 2019). While health care spending primarily emphasizes the treatment of disease, governments can consider allocating spending to other areas such as social services, which impact health through prevention and promotion. For example, social spending is related to decreased rates of potentially avoidable mortality due to poor access to treatment, specific health behaviours such as smoking, and/or environmental changes, as well as increased life expectancy (Dutton et al, 2018). In Canada, redistributing spending between social and health spending is a relatively small change which can improve population health (Dutton et al., 2018). Canada's public health system lags 
behind other OECD countries in expending resources for citizen supports (Raphael, 2017). Growing evidence highlights that income inequalities, health, and mortality rates improve when countries financially prioritize public services spending (McCartney et al., 2019). Government spending in areas such as affordable housing, the climate crisis, childcare, public transit, and health promotion are accessible ways to implement a health-in-all policies approach (Kershaw, 2018).

\section{Limitations}

The current research does not seek to perform a meta-analysis or meta-synthesis with the findings of the review. Interpretations of the results stated here should be taken with an understanding of the limitations of the current research and those of the included articles. Most included articles were observational in nature, thus eliminating the possibility of determining causality. Much of the included research uses aggregated data which does not consider the heterogeneity of the studied populations and can lead to ecological fallacy; that is, inaccurately drawing conclusions about individuals from aggregated data (Finney et al., 2011).

Further, it is difficult to measure all possible population health outcomes, and the included research only makes connections with a few of these. There are likely other population health outcomes being impacted by public health reform, but the included literature does not address this. Finally, research involving health equity is limited through inconsistent definition and usage of the term. For example, in their review, Bambra and colleagues (2014) discuss health equity primarily in terms of equitable access to care. Although this definition is related to our own, it is narrower, which makes it difficult to draw accurate conclusions.
Despite these limitations, the findings of this review are important for opening the discussion around the impact of public health system reform in Canada on population health outcomes and health equity.

\section{Conclusion}

Canada's acute healthcare system has been continually overburdened with increasing rates of preventable chronic diseases, and this has been exacerbated by the onset of the global COVID-19 pandemic. Now, more than ever, the importance of ensuring strong public health systems has been highlighted in Canada and around the world. However, changes have been happening to public health systems across Canada with limited attention to population health outcomes since numerous public health crises in the early 2000s (e.g., SARS, Walkerton E-Coli, H1N1, etc.). Thus, the time for meaningful, evidence-informed changes in the public health system is apparent. The goal of the current research was to examine how public health reform impacts the population health outcomes of Canadians. The findings of this review highlight the paucity of literature on this subject. Further research is required to identify the population health impacts of structural changes to the organization, governance, financing, and delivery of public health in Canada.

\section{Ethical Permissions}

N/A due to the lack of human and/or animal participants

\section{Declaration of Conflicting Interests}

The author(s) declare no potential conflicts of interest with respect to the research, authorship and publication of this article.

\section{Funding}

The author(s) received no financial support for the research, authorship and publication of this article. 


\section{References}

Alexis, O. \& Vydelingum V. (2004). The lived experiences of overseas black and minority ethnic nurses in the National Health Service in the south of England. Diversity Health Social Care, 1(1), 13 20.

Andruszkiewicz, N., Ogunniyi, C., Carfagnini, C., Branston, A. \& Hirji, M. M. (2019). Utilizing public health core competencies to share data effectively with community organizations to promote health equity. Canadian Journal of Public Health, 110, 303-313. https://doi.org/10.17269/s41997-01900190-8

Bambra, C., Garthwaite, K. \& Hunter, D. (2014). All things being equal: Does it matter for equity how you organize and pay for health care? A review of the international evidence. International Journal of Health Services, 44(3), 45777. https://doi.org/10.2190/HS.44.3.c

Baum, F., Delany-Crowe, T., MacDougall, C., van Eyk, H., Lawless, A., Williams, C., $\&$ Marmot, M. (2019). To what extent can the activities of the South Australian Health in All Policies initiative be linked to population health outcomes using a program theory-based evaluation? BMC Public Health, 19(88), 1-16. https://doi.org/10.1186/s12889-0196408-y

Beaudet, N., Richard, L., Gendron, S., \& Boisvert, N. (2011). Advancing population-based health-promotion and prevention practice in community-health nursing. Advances in Nursing Science, 34(4), E1-E12. https://doi.org/10.1097/ANS.0b013e318 2300d9a

Brownson, R. C., Allen, P., Duggan, K., Stamatakis, K. A., \& Erwin, P. C. (2012). Fostering more-effective public health by identifying administrative evidence-based practices: : A review of the literature. American Journal of Preventive Medicine, 43(3), 309-19. https://doi.org/10.1016/j.amepre.2012.0 $\underline{6.006}$

Buck-McFadyen, E. \& MacDonnell, J. (2017). Contested practice: Political activism in nursing and implications for nursing education. International Journal of Nursing Education Scholarship, 14(1), 1-13. https://doi.org/10.1515/ijnes-2016$\underline{0026}$

Canadian Network of Public Health Associations (CNPHA). (2019). A collective voice for advancing public health: Why public health associations matter today. Canadian Journal of Public Health, 110, 335-339. https://doi.org/10.17269/s41997-019$\underline{00197-1}$

Canadian Public Health Association (CPHA). (2017). Public health: A conceptual framework. https://www.cpha.ca/sites/default/files/u ploads/resources/cannabis/cpha_public health_conceptual_framework_e.pdf

Canadian Public Health Association (CPHA). (May 2019). Public health in the context of health system renewal in Canada: Position statement. https://www.cpha.ca/public-healthcontext-health-system-renewal-canada

Critical Appraisal Skills Programme (CASP). (2018a). CASP case control study checklist. https://casp-uk.net/wpcontent/uploads/2018/01/CASP-CaseControl-Study-Checklist.pdf

Critical Appraisal Skills Programme (CASP). (2018b). CASP cohort study checklist. https://casp-uk.net/wpcontent/uploads/2018/01/CASP-CohortStudy-Checklist.pdf

Demaio, A., \& Marshall, R. (2018). Social lobbying: A call to arms for public health. Lancet, 391(10130), 1558-1559. https://doi.org/10.1016/S01406736(18)30831-6

Dobbins, M. (2017). Rapid review guidebook: Steps for conducting a rapid review. Version 1.2. Hamilton, ON: National Collaborating Centre for Methods and Tools. 
The Canadian Journal of Critical Nursing Discourse

See it. Speak it. Write it. Change it.

http://www.nccmt.ca/uploads/media/me dia/0001/01/ce4c0813b3639ccd87bb6e5 ad716df144209109e.pdf

Dutton, D. J., Forest, P. G., Kneebone, R. D., \& Zwicker, J. D. (2018). Effect of provincial spending on social services and health care on health outcomes in Canada: An observational longitudinal study. Canadian Medical Association Journal, 190, E66-E71. https://doi.org/10.1503/cmaj.170132

Erwin, P. C., Greene, S. B., Mays, G. P., Ricketts, T. C., \& Davis, M. V. (2011). The association of changes in local health department resources with changes in state-level health outcomes. American Journal of Public Health, 101(4), 609-615. https://doi.org/10.2105/AJPH.2009.1774 $\underline{51}$

Erwin, P. C., Mays, G. P., \& Riley, W. J. (2012). Resources that may matter: The impact of local health department expenditures on health status. Public Health Reports, $127,89-95$.

https://doi.org/10.1177/0033354912127 $\underline{00110}$

Fafard, P. (2018). Contested roles of Canada's Chief Medical Officers of Health. Canadian Journal of Public Health, 109, 585-589. https://doi.org/10.17269/s41997-0180080-3

Falk-Rafael, A. \& Betker, C. (2012). Witnessing social injustice downstream and advocating for health equity upstream: "The trombone slide" of nursing. Advances in Nursing Science, 35(2), 98112.

https://doi.org/10.1097/ANS.0b013e318 24fe70f

Finney, J. W., Humphreys, K., Kivlahan, D. R. \& Harris, A. H. S. (2011). Why health care process performance measures can have different relationships to outcomes for patients and hospitals:Understanding ecological fallacy. American Journal of Public Health, 101(9), 1635-
42. https://doi.org/10.2105/AJPH.2011.3 00153

Fiset-Laniel, J., Guyon, A., Perreault, R., \& Strumpf, E. C. (2020). Public health investments: Neglect or wilful omission? Historical trends in Quebec and implications for Canada. Canadian Journal of Public Health, 111(3), 383388. https://doi.org/10.17269/s41997020-00342-1

Fotaki, M., Roland, M., Boyd, A., McDonald, R., Scheaff, R. \& Smith, L. (2008). What benefits will choice bring to patients? Literature review and assessment of implications. Journal of Health Services Research \& Policy, 13(3), 178-184. https://doi.org/10.1258/jhsrp.2008.0071 $\underline{63}$

Gelormino, E., Bambra, C., Spadea, T., Bellini, S. \& Giuseppe, C. (2011). The effects of health care reforms on inequalities: A review and analysis of the European evidence base. International Journal of Health Services, 41(2), 209-230. https://doi.org/10.2190/HS.41.2.b

Gepkens, A. \& Gunning-Schepers, L. (1996). Interventions to reduce socio-economic health differences: A review of the international literature. European Journal of Public Health, 6, 218-226. https://doi.org/10.1093/eurpub/6.3.218

Grembowski, D., Bekemeir, B., Conrad, D., \& Kreuter, W. (2010). Are local health department expenditures related to racial disparities in mortality? Social Science $\&$ Medicine, 71(12), 2057-65. https://doi.org/10.1016/j.socscimed.2010 .09 .004

Guyon, A., \& Perreault, R. (2016). Public health systems under attack in Canada:

Evidence on public health system performance challenges arbitrary reform. Canadian Journal of Public Health, 107(3), e326-e329. https://doi.org/10.17269/CJPH.107.5273

Guyon, A., Hancock, T., Kirk, M., MacDonald, M., Neudorf, C., Sutcliffe, P., Talbot, J. \& Watson-Creed, G. (2017). 
The weakening of public health: A threat to population health and health care system sustainability [Editorial]. Canadian Journal of Public Health, 108(1), e1-e6. https://doi.org/10.17269/CJPH.108.6143 Hanratty, B., Zhang, T. \& Whitehead, M. (2007).

How close have universal health systems come to achieving equity in use of curative services? A systematic review. International Journal of Health Services, 37(1), 89-109. https://doi.org/10.2190/TTX2-3572UL81-62W7

Hayes, S. L., Mann, M. K., Morgan, F. M., Kelly, M. J. \& Weightman, A. L. (2012). Collaboration between local health and local government agencies for health improvement. Cochrane Database of Systematic Reviews. https://doi.org/10.1002/14651858.CD00 7825.pub6.

Health Evidence. (2016). Quality assessment tool-Review articles.

https://www.healthevidence.org/docume nts/our-appraisaltools/QA_Tool\&Dictionary_10Nov16.p $\mathrm{df}$

Hyde, J. \& Shortell, S. M. (2012). The structure and organization of local and state public health agencies in the U.S.: A systematic review. American Journal of Preventive Medicine, 42(5 Suppl 1), S29-41. https://doi.org/10.1016/j.amepre.2012.0 1.021

Joanna Briggs Institute (JBI). (2017). Critical appraisal checklist for text and opinion papers. http://joannabriggs.org/assets/docs/critic al-appraisaltools/JBI_Critical_AppraisalChecklist_for_Text_and_Opinion2017.p df

Kershaw, P. (2018). The need for health in all policies in Canada. Canadian Medical Association Journal, 190(3), E64-E65. https://doi.org/10.1503/cmaj.171530
Kirk, M. (2020). When it is no longer your call: Managing the eroding public health nurse role [Doctoral dissertation, University of Victoria]. https://dspace.library.uvic.ca/bitstream/h andle/1828/11785/Kirk_Megan_PhD_20 20.pdf? sequence $=1 \&$ is Allowed $=y$

Kirk, M., Tomm-Bonde, L., \& Schreiber, R. (2014). Public health reform and health promotion in Canada. Global Health Promotion, 21(2), 15-22. https://doi.org/10.1177/1757975913512 157

Mays, G. P., Halverson, P. K. \& Scutchfield, F. D. (2003). Behind the curve? What we need to know from public health systems research. Journal of Public Health Management and Practice, 9(3), 179-82. https://doi.org/10.1097/00124784200305000-00001

Mays, G., Smith, S. A., Ingram, R.C., Racster, L. J., Lamberth, C. D., \& Lovely, E.S. (2009). Public health delivery systems: Evidence, uncertainty, and emerging research needs. American Journal of Preventive Medicine, 42, p. 214-220. http://doi.org/10.1016/j.amepre.2008.11. 008

Mays, G. P. \& Smith, S. A. (2011). Evidence links increases in public health spending to declines in preventable deaths. Health Affairs, 30(8), 1-9. https://doi.org/10.1377/hlthaff.2011.019 $\underline{6}$

McCartney, G., Hearty, W., Arnot, J., Popham, F., Cumbers, A. \& McMaster, R. (2019). Impact of political economy on population health: A systematic review of reviews. American Journal of Public Health, 109(6), e1-e12. https://doi.org/10.2105/AJPH.2019.3050 $\underline{01}$

McGibbon, E. \& Lukeman, S. (2019). Critical social justice: The moral imperative for critical perspectives in nursing. Witness: The Canadian Journal of Critical Nursing Discourse, 1(1), 3-12. https://doi.org/10.25071/2291-5796.21 
McLaren, L., Braitstein, P., Buckeridge, D., Contandriopoulos, D., Creatore, M. I., Faulkner, G., Hammond, D., Hoffman, S. J., Kestens, Y., Leatherdale, S., McGavock, J., Norman, W. V., Nykiforuk, C., Ridde, V., \& Smylie, J. (2019). Why public health matters today and tomorrow: The role of applied public health research. Canadian Journal of Public Health, 110, 317-322. https://doi.org/10.17269/s41997-01900196-2

Ministers of Health and Health

Promotion/Healthy Living. (2010). Creating a healthier Canada: Making prevention a priority - a declaration on prevention and promotion from Canada's Ministers of Health and Health Promotion/Healthy Living, Public Health Agency of Canada. http://www.phac-aspc.gc.ca/hp-ps/hlmvs/declaration/pdf/dpp-eng.pdf

National Collaborating Centre for Determinants of Health (NCCDH). (2013). Let's talk: Public health roles for improving health equity. National Collaborating Centre for Determinants of Health, St. Francis Xavier University. https://nccdh.ca/resources/entry/letstalk-public-health-roles

NCCDH. (2015). Equity-integrated population health status reporting: Action framework. National Collaborating Centre for Determinants of Health, St. Francis Xavier University. https://nccdh.ca/resources/entry/equityintegrated-population-health-statusreporting-action-framework

NCCDH. (2018a). A gaps analysis to improve health equity knowledge and practices. National Collaborating Centre for Determinants of Health, St. Francis Xavier University. https://nccdh.ca/images/uploads/comme nts/A gaps analysis to improve health _equity_knowledge_and_practices_EN_ Final.pdf

NCCDH. (2018b). Building a culture of equity in Canadian public health: An environmental scan. National Collaborating Centre for Determinants of Health, St. Francis Xavier University. https://nccdh.ca/resources/en try/building-a-culture-of-equity-2017environmental-scan

Naylor, D., Basrur, S., Bergeron, M., Brunham, R., Butler-Jones, D., Dafoe, G., Lussing, F., McGeer, A., Neufeld, K. R., \& Plummer, F. (2003). Learning from SARS: Renewal of public health in Canada. Public Health Agency of Canada. https://www.canada.ca/en/publichealth/services/reportspublications/learning-sars-renewalpublic-health-canada.html

Pinto, A. D., Manson, H., Pauly, B., Thanos, J., Parks, A., \& Cox, A. (2012). Equity in public health standards: A qualitative document analysis of policies from two Canadian provinces. International Journal for Equity in Health, 11(28), 110. https://doi.org/10.1186/1475-927611-28

Potvin, L. (2014). Canadian public health under siege [Editorial]. Canadian Journal of Public Health, 105(6), e401-403. https://doi.org/10.17269/cjph.105.4960

Public Health Agency of Canada (PHAC). (2008). Core Competencies for Public Health in Canada. http://www.phacaspc.gc.ca/php-psp/ccph-cesp/pdfs/ccmanual eng090407.pdf

Ransom, J., Schaff, K., \& Kan, L. (2012). Is there an association between local health department organizational and administrative factors and childhood immunization coverage rates? Journal of Health and Human Services Administration, 34(4), 418-55. https://pubmed.ncbi.nlm.nih.gov/225302 $\underline{85 /}$

Raphael, D. (2015). Beyond policy analysis: The raw politics behind opposition to healthy public policy. Health Promotion International,30, 380-396. https://doi.org/10.1093/heapro/dau044 Raphael, D. (2017). Implications of inequities in 
health for health promotion practice. In E. Rootman, A. Pederson, K. L. Frohlich, \& S. Dupéré (Eds.), Health promotion in Canada: New perspectives on theory, practice, policy, and research (4th ed.), (pp.146-166). Canadian Scholars.

Schick-Makaroff, K., MacDonald, M., Plummer, M., Burgess, J., \& Neander, W. (2016). What synthesis methodology should I use? A review and analysis of approaches to research synthesis. AIMS Public Health, 3(1), 172-215. https://doi.org/10.3934/publichealth.201 6.1 .172

Schofield, R., Ganann, R., Brooks, S., McGugan, J., Dalla Bona, K., Betker, C., Dilworth, K., Parton, L., ReidHaughian, C., Slepkov, M. \& Watson, C. (2010). Community health nursing vision for 2020: Shaping the future. Western Journal of Nursing Research, 33(8), 1047-1068. https://doi.org/10.1177/0193945910375 819

Scutchfield, F. D., Ingram, R. C. (2013). Public health systems and services research: Building the evidence base to improve public health practice. Public Health Review, 35(1). https://doi.org/10.1007/BF03391693

Singh, S. R. (2014). Public health spending and population health: A systematic review. American Journal of Preventive Medicine, 45(5), 634-640. https://doi.org/10.1016/j.amepre.2014.0 5.017

Smith, M. J., Thompson, A. \& Upshur, R. E. G. (2018). Is 'health equity' bad for our health? A qualitative empirical ethics study of public health policy-makers' perspectives. Canadian Journal of Public Health, 109, 633-642. https://doi.org/10.17269/s41997-0180128-4

Strosher, W., MacDonald, M. \& Hancock, T. (2012). Advancing public health systems and services research in Canada: Developing a pan-Canadian agenda. Proceedings from: Canadian Public Health Systems and Services Research Think Tank. Montreal, Quebec. 2011 May 26-27. https://www.uvic.ca/research/groups/cph fri/assets/docs/PHSSR_Think_Tank_rep ort_Final.pdf

Thomson, D. R., Amoroso, C., Atwood, S., Bonds, M. H., Rwabukwisi, F. C., Drobac, P., Finnegan, K. E., Bertrand Farmer, D., Farmer, P. E., Habinshuti, A., Hirschhorn, L. R., Manzi, A., Niyigena, P., Rich, M. L., Stulac, S., Murray, M. B. \& Binaqwaho, A. (2017). Impact of a health system strengthening intervention on maternal and child health outputs and outcomes in rural Rwanda 2005-2010. BMJ Global Health, 3, 1-11. https://doi.org/10.1136/bmigh-2017$\underline{000674}$ 
The Canadian Journal of Critical Nursing Discourse

See it. Speak it. Write it. Change it.

Table 1: Rapid Review Search Results

\begin{tabular}{lllll}
\hline Search Attempt & Hits & $\begin{array}{l}\text { Excluded at Title and } \\
\text { Abstract Stage }\end{array}$ & $\begin{array}{l}\text { Full Papers } \\
\text { Examined }\end{array}$ & $\begin{array}{l}\text { Included in Final } \\
\text { Analysis }\end{array}$ \\
\hline $\begin{array}{l}\text { Keywords + "population health } \\
\text { outcomes" + canad* }\end{array}$ & 26 & 21 & 5 & 1 \\
$\begin{array}{l}\text { Keywords + "health outcomes" } \\
+ \text { canad* }\end{array}$ & 186 & 182 & 4 & 0 \\
$\begin{array}{l}\text { Keywords + "population health } \\
\text { outcomes" }\end{array}$ & 22 & 20 & 3 & 2 \\
\begin{tabular}{l} 
Reference Lists \\
\hline
\end{tabular} & N/A & N/A & 7 & 4 \\
\hline
\end{tabular}


The Canadian Journal of Critical Nursing Discourse

See it. Speak it. Write it. Change it.

Table 2: Description of Methodology of the Included Studies

\begin{tabular}{|c|c|c|}
\hline $\begin{array}{l}\text { Authors \& Year of } \\
\text { Publication }\end{array}$ & Data Source(s) & Analytic Method \\
\hline $\begin{array}{l}\text { Erwin, Green, Mays, } \\
\text { Ricketts \& Davis, } \\
2011\end{array}$ & $\begin{array}{l}\text { National Association of County and City Health } \\
\text { Officials (NACCHO) survey \& America's Health } \\
\text { Rankings (AHR) survey }\end{array}$ & $\begin{array}{l}\text { Spearman rank correlation } \\
\& \text { multivariate regression }\end{array}$ \\
\hline Mays \& Smith, 2011 & $\begin{array}{l}\text { NACCHO; Health Resources and Services } \\
\text { Administration's Area Resource File; Census } \\
\text { Bureau's Consolidated Federal Funds Report and } \\
\text { Census of Governments; Centers for Disease Control } \\
\text { and Prevention's Compressed Mortality File }\end{array}$ & $\begin{array}{l}\text { Multivariate regression } \\
\text { models; instrumental } \\
\text { variables methods; } \\
\text { specification tests }\end{array}$ \\
\hline $\begin{array}{l}\text { Erwin, Mays \& Riley, } \\
2012\end{array}$ & NACCHO; AHR & $\begin{array}{l}\text { Fixed-effects regression } \\
\text { model }\end{array}$ \\
\hline $\begin{array}{l}\text { Bambra, Garthwaite, } \\
\& \text { Hunter, } 2014\end{array}$ & $\begin{array}{l}\text { Cochrane Database of Systematic Reviews (CDSR), } \\
\text { Database of Abstracts of Reviews of Effects } \\
\text { (DARE), Campbell Collaboration Database, } \\
\text { PROSPERO, EPPI-Centre database of health } \\
\text { promotion and public health studies, Applied Social } \\
\text { Sciences Index and Abstracts (ASSIA) and Medline; } \\
\text { Citation follow up }\end{array}$ & $\begin{array}{l}\text { Methodological quality of } \\
\text { systematic reviews } \\
\text { appraised using adapted } \\
\text { DARE criteria }\end{array}$ \\
\hline Singh, 2014 & $\begin{array}{l}\text { Medline (via PubMed) and JSTOR; Gray literature } \\
\text { via Google Scholar; "related articles" function in } \\
\text { PubMed; "cited by" and "related articles" functions } \\
\text { in Google Scholar }\end{array}$ & $\begin{array}{l}\text { Articles screened for } \\
\text { eligibility; Data extracted } \\
\text { into tables }\end{array}$ \\
\hline $\begin{array}{l}\text { Guyon \& Perreault, } \\
2016\end{array}$ & Not specified & Not specified \\
\hline $\begin{array}{l}\text { Thomson, Amoroso, } \\
\text { Atwood, Bonds, } \\
\text { Rwabukwisi, Drobac, } \\
\text {... Binagwaho, } 2017\end{array}$ & Rwanda Demographic and Health Survey (RDHS) & $\begin{array}{l}\text { Composite coverage index } \\
\text { (CCI) calculated to } \\
\text { monitor overall health } \\
\text { coverage across time; } \\
\text { Ordinary least squares } \\
\text { regression with group, } \\
\text { year and group-year } \\
\text { interaction terms; } \\
\text { DHS synthetic life-table } \\
\text { approach (to model change } \\
\text { in childhood mortality } \\
\text { rates); } \\
\text { Taylor linearized variance } \\
\text { estimation in regression } \\
\text { models and jackknife } \\
\text { repeated replications }\end{array}$ \\
\hline
\end{tabular}


Table 3: Data extraction: Variables \& Key Findings

\begin{tabular}{lll}
\hline $\begin{array}{l}\text { Authors, Year of } \\
\text { Publication } \\
\text { (Origins of Study) }\end{array}$ & Independent Variable(s) & Dependent/ Outcome Variable(s) \\
\hline $\begin{array}{lll}\text { Erwin et al, 2011 } \\
\text { (U.S.) }\end{array}$ & $\begin{array}{l}\text { Changes in local health } \\
\text { department (LHD) } \\
\text { expenditures and staffing } \\
\text { per capita, aggregated to the } \\
\text { state level }\end{array}$ & $\begin{array}{l}\text { 7 health measures: smoking and } \\
\text { obesity prevalence, infectious } \\
\text { disease morbidity, infant mortality, } \\
\text { mortality from cardiovascular } \\
\text { disease (CVD) and cancer, and } \\
\end{array}$ \\
& years of potential life lost (YPLL)
\end{tabular}

Mays \& Smith, $\quad$ Per capita local public 2011 (U.S.) health spending

Erwin et al., $2012 \quad$ LHD expenditures, (U.S.) aggregated to the state level

Bambra et al., 2014 (U.K.)

Singh, 2014

(U.S.)

Guyon \&

Perreault, 2016

(Canada)

Thomson et al., 2017 (Rwanda)
Organizational and financial health system interventions
Public health spending

Elements of public health systems (e.g., financial resources, workforce, population size, organizational structure)
Age-adjusted all-cause mortality rate; infant mortality rate; ageadjusted mortality rates for heart disease, cancer, diabetes, and influenza

7 health measures: smoking and obesity prevalence, infectious disease morbidity, infant mortality, deaths due to cardiovascular disease and cancer, overall premature death (years of potential life lost/YPLL)

Equity of health care (access and outcomes)

Population health outcomes

Processes or outcomes of public health systems
Key Findings

Changes in expenditures per capita is negatively associated with infectious disease morbidity ( $\mathrm{r}=-$ 0.3407; $p=.0272)$ and CVD deaths ( $\mathrm{r}=-0.3723$; $p=.015$ ). Fulltime equivalents (FTEs) per capita is negatively associated with CVD deaths ( $\mathrm{r}=-$ 0.3689 ; $p=0.16$ )"

These findings are confirmed with multiple linear regression

Increases in $\mathrm{PH}$ spending is associated with reduced rates of the following population health outcomes: infant deaths, heart disease deaths, diabetes deaths, and cancer deaths (all $p$ 's $<.05$ )

Increases in LHD spending is associated with decreased infectious disease morbidity $(\mathrm{t}=-3.28$; $p=0.002)$ and in YPLL ( $\mathrm{t}=-2.73 ; p=0.008)$.

Spending increase of $\$ 10$ per capita decreases infectious disease morbidity by $7.4 \%$, and YPLL decreased by $1.5 \%$.

The systematic review level research shows that there are inconclusive or negative impacts on equitable health access and health outcomes as a result of health care reform. Examples include negative impacts related to private insurance, for-profit health care providers, marketization, and privatization. Integrating health and social systems had inconclusive impacts on health equity.

Some population health outcomes, such as cardiovascular disease mortality and rates of infectious disease, are positively impacted by increased PH spending. There is little evidence linking improved health disparities and $\mathrm{PH}$ spending. The pathways that mediate increased spending and improved outcomes are unclear.

Increased financial resources, increased staffing per capita, a population size between 50,000 and 500,000 , and specific administrative features are all related to increased productivity in public health systems.

Increased financial resources and increased staffing per capita are significantly associated with improved population health outcomes, including decreased rates of cardiovascular disease mortality and rates of infectious disease morbidity.

Overall, improvements population health outcomes improved in both groups, but the intervention group exhibited greater improvements in rates of diarrhea, acute respiratory infection, and fever. The intervention area showed a $12.8 \%$ decline in under-five mortality and the other rural areas by $8.9 \%$. indicators: neonatal, infant an under-five mortality; adult mortality; recent occurrence of ARI, diarrhea or fever in children $<5$; stunting and wasting in children $<5$

\title{
Table 4: Addressing Health Equity in the Included Articles
}

Rwandan Ministry of Health Population health outcomes (RMOH) and Partners In Health (PIH) interventions

(1)


The Canadian Journal of Critical Nursing Discourse

See it. Speak it. Write it. Change it.

\begin{tabular}{|c|c|c|c|}
\hline $\begin{array}{l}\text { Author(s) \& Year of } \\
\text { Publication }\end{array}$ & $\begin{array}{l}\text { Health Equity } \\
\text { Addressed in } \\
\text { the Article? }\end{array}$ & $\begin{array}{l}\text { Health Equity } \\
\text { is an Outcome } \\
\text { Variable? }\end{array}$ & How Was Health Equity Discussed? \\
\hline $\begin{array}{l}\text { Thomson, Amoroso, } \\
\text { Atwood, Bonds, } \\
\text { Rwabukwisi, Drobac, } \\
\text {.. Binagwaho, } 2017\end{array}$ & Yes & No & $\begin{array}{l}\text { Health equity was a major component of } \\
\text { Vision } 2020 \text {, a government initiative. } \\
\text { The RMOH-PIH intervention focused on } \\
\text { equity, infrastructure, financial resources } \\
\text { and staffing. } \\
\text { The concept of health equity was used to } \\
\text { direct the development of the RMOH-PIH } \\
\text { intervention. }\end{array}$ \\
\hline $\begin{array}{l}\text { Guyon \& Perreault, } \\
2016\end{array}$ & Yes & No & $\begin{array}{l}\text { Equity is defined as an element of public } \\
\text { health performance: "the responsibility to } \\
\text { dispense public health services within a } \\
\text { population in such a way as to reduce } \\
\text { health disparities" (p. e } 327 \text { ). } \\
\text { PHSSR research often examines public } \\
\text { health performance, but there is a focus } \\
\text { on productivity more so than equity. }\end{array}$ \\
\hline $\begin{array}{l}\text { Bambra, Garthwaite, \& } \\
\text { Hunter, } 2014\end{array}$ & Yes & Yes & $\begin{array}{l}\text { Private insurance: negative health equity } \\
\text { impact. } \\
\text { Free-care programs: positive health equity } \\
\text { impact. } \\
\text { Increased user fees and out-of-pocket } \\
\text { payments: negative impact. } \\
\text { Marketization of health care services: } \\
\text { negative or inconclusive impacts. } \\
\text { Integration of health and social services: } \\
\text { inconclusive impact. }\end{array}$ \\
\hline Singh, 2014 & Yes & Yes & $\begin{array}{l}\text { Health disparities is considered an } \\
\text { outcome variable, specifically relating to } \\
\text { disparities in mortality between races. } \\
\text { Limited evidence that increased spending } \\
\text { contributes to reduced health disparities. }\end{array}$ \\
\hline $\begin{array}{l}\text { Erwin, Green, Mays, } \\
\text { Ricketts \& Davis, } 2011\end{array}$ & No & N/A & N/A \\
\hline Mays \& Smith, 2011 & No & N/A & N/A \\
\hline
\end{tabular}

